\title{
A Self-Actuated Cellular Protein Delivery Machine
}

\author{
Recep Erdem Ahan, ${ }^{\dagger, \ddagger}$ Büşra Merve Kirpat, ${ }^{\dagger, \ddagger}$ Behide Saltepe, ${ }^{\dagger, \ddagger}$ and Urartu Özgür Şafak Şeker*, ${ }^{\dagger, \ddagger, \S_{0}}$ \\ ${ }^{\dagger}$ UNAM-National Nanotechnology Research Center, Bilkent University, 06800 Ankara, Turkey \\ ${ }^{\ddagger}$ Institute of Materials Science and Nanotechnology, Bilkent University, 06800 Ankara, Turkey \\ ${ }^{\S}$ Neuroscience Graduate Program, Bilkent University, 06800 Ankara, Turkey
}

\section{Supporting Information}

\begin{abstract}
Engineered bacterial cells have great promise to solve global problems, yet they are hampered by a lack of convenient strategy for controlled protein release. A wellcontrolled protein translocation through cellular membranes is essential for cell-based protein delivery. Here we have developed a controlled protein release system by programming a bacterial autotransporter system named Ag43. Ag43 protein is engineered by adding a protease digestion site between its translocation and cargo domains. Once it is displayed on the cell surface, we managed to release the cargo proteins in defined conditions by processing environmental signals. The protein release in terms of time and quantity can

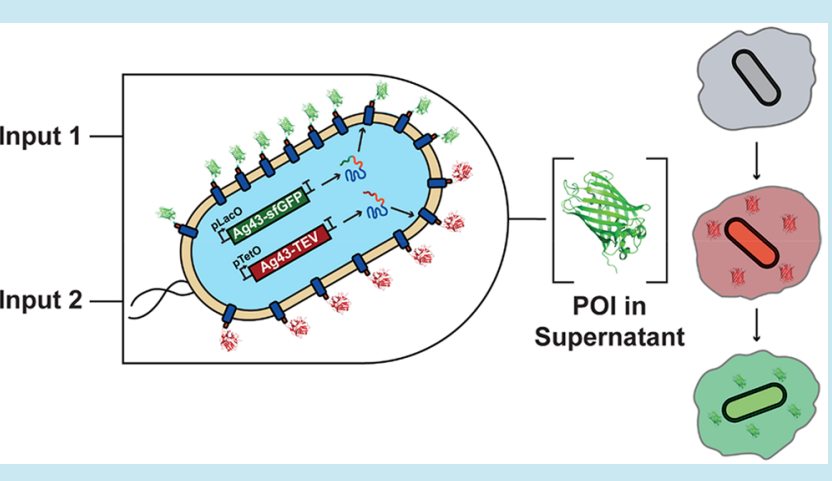
be controlled through changing the inducer conditions. We thought that the release system can be adopted for complex genetic circuitries due to its simplicity. We implemented the protein release system to develop a cellular device that is able to release proteins in a sequence response to ordered chemical signals. We envision that development of genetically controlled protein release systems will improve the applications of synthetic organisms in cell based therapies, especially for cases with a need for controlled protein release using the cues from the biological environment.
\end{abstract}

KEYWORDS: sequential secretion, autotransporters, TEV protease, protein display

S ynthetic biology aims to develop genetically engineered organisms that are capable of recording, computing, and responding external signals. ${ }^{1}$ For this purpose, various logic and memory genetic circuits have been developed by using transcription factors, ${ }^{2-4}$ RNA-based regulators, ${ }^{5-7}$ and DNA arranging serine integrases. ${ }^{8,9}$ As a subclass of site-specific recombinases, serine integrases are utilized by bacteriophages for incorporation of their genomic DNA to bacterial genome via using attB (bacteria) and attP (phage) sites in nature, yet recombinase-based memory and logic circuits are engineered by aligning the attB and attP sites on a same plasmid with different directions. ${ }^{10}$ Recombinases are used to build genetic circuits that are able to amplify signals, regulate metabolic pathways, and record signals on DNA. ${ }^{11-15}$ Because there are recombinases that rearrange DNA irreversibly, signals permanently can be recorded on a heritable DNA (genomic or plasmid), and cells are locked in a defined state. Such an approach is metabolically more economical compared to other genetic circuits. ${ }^{10}$ In a recent study, it is shown that the temporal order of signals can be recorded by using different serine integrases. ${ }^{16}$ Using similar approaches, recombinase implemented stable biological states can be used to build engineered systems for controlled and sequential secretion of multiple proteins upon receiving ordered signals.
Secretion of recombinant proteins to extracellular milieu by engineered microorganisms is a challenging but desired task for many biotechnological applications including protein based drug production, engineered probiotics for therapeutic purposes. Additionally, carrying proteins across cellular membranes is an indispensable task for processing indiffusible substances (e.g., alginate, cellulose) by whole cell biocatalysts, or for insoluble recombinant proteins based materials such as silk and functional amyloids. ${ }^{17-21}$ Furthermore, production of biologic agents in point-of-care devices offers the production of therapeutics in short time frames without a need for complex settings. Combination of cellular protein secretion with these devices may ease downstream purification as well as lower cellular contaminants such as endotoxins. ${ }^{22,23}$

Escherichia coli (E. coli) has been engineered to secrete proteins to extracellular medium using different approaches. ${ }^{24}$ Dedicated protein secretory machineries such as type I secretion system (TI-SS) or type III secretion system (TIIISS) from pathogenic strains were employed to build engineered secretion systems in E. coli. In those secretion systems, generally a secretion tag (mostly a short peptide sequence) is fused with a protein-of-interest (POI) to facilitate

Received: February 12, 2019

Published: February 27, 2019 
extracellular secretion. ${ }^{25,26}$ Alternatively, YebF and OsmY proteins can be fused as secretion partners to the POI to secrete the fusion protein to the extracellular medium through periplasm without the need of reconstitution of any special secretory machinery. ${ }^{27-29}$ The secretion partner proteins can transfer fused proteins to their C-terminal without causing a loss of outer membrane integrity. ${ }^{30}$ However, the fusion tags remain uncleaved after secretion in both cases. ${ }^{22,26,31}$ Also overexpressing a recombinant secretion machinery of TI-SS and TIII-SS in cells can be costly in terms of cellular economy because these recombinant systems consist of large gene clusters encoding multiple proteins. ${ }^{32-35}$ Therefore, development of sophisticated genetic circuits in cells to secrete POIs suffers from high metabolic burden of secretion machineries and uncleaved secretion tags.

Autotransporter superfamily secretes their passenger domains to cell surface via type $\mathrm{V}$ secretion pathway. ${ }^{36}$ Type $\mathrm{V}$ secretion is a two-step secretion pathway in which translated polypeptide chain, which is composed of $\mathrm{N}$-terminal signal sequence, a passenger domain, and a C-terminal $\beta$-barrel translocation domain, is secreted to periplasm with SecYEG translocon. Subsequent to secretion, $\beta$-barrel structures are formed and are inserted into outer membrane. After $\beta$-barrel formation, the passenger domain is secreted to the cell surface. ${ }^{37}$ Although it has been assumed that all information for secretion is encoded in primary protein sequence, it is reported in a recent study that other periplasmic accessory proteins such as Bam-TamA/B complex are necessary for functional secretion. ${ }^{38}$ The autotranporters are attractive candidates for biotechnological applications as bacterial surface display platform because of their simple secretion pathway, high copy number on cell surface (up to 100000 copy per cell), and ability to display various fusion partners. ${ }^{39}$ However, the passenger domains are not truly secreted extracellular environment. They remain attached to cell surface via either covalent or noncovalent interactions. ${ }^{40}$

The site-specific proteases, such as tobacco etch virus protease (TEVp), factor Xa protease, human rhinovirus protease, Ulp1 protease, and many others recognize and cleave short unique peptide sequences or certain motifs. Thanks to their specificity, they are utilized in different biotechnological applications, for instance, removal of unwanted fusion tags. ${ }^{41}$ In addition, site-specific proteases are used to construct logic gates and intracellular processing systems in recent studies. ${ }^{42,43}$ Therefore, it is possible to engineer a controlled protein release by using site specific protease.

In this study, we developed a novel bifunctional cellular device to display and secrete POI in defined conditions. To engineer the system, POI is displayed on the surface of $E$. coli by fusing with $\mathrm{Ag} 43$ autotransporter protein. $\mathrm{TEV}$ p recognition site is added between POI and truncated $\alpha$-passenger domain to facilitate release. POI can be released to medium upon display of TEVp on the cell surface. The amount of released protein can be tuned with controlling the amount of TEVp on cell surface. Due to its simplicity, the system can be used to build complex genetic circuit to perform different tasks. In the next step, we have engineered a release system to secrete multiple proteins in an order with a programmable manner. To secrete POIs sequentially in response to ordered signals, stable biological states are established using recombinases. The engineered cells are able to secrete two different proteins upon receiving the chemical signals in a defined order. We envision that the proposed protein release system can be used in complex processes that require secretion of different proteins sequentially, and can be implemented in complex genetic circuitries because of its simplicity and modularity.

\section{MATERIALS AND METHODS}

Cell Strains and Plasmid Constructions. E. coli $\mathrm{DH} 5 \alpha$ PRO strain was used as a host for cloning. Cell stocks were maintained at $-80{ }^{\circ} \mathrm{C}$ in $25 \%$ glycerol in Lysogeny Broth (LB) solution. This strain contains PRO cassette which encodes elements for constitutively active expression of TetR and LacI repressor and resistance gene to spectinomycin. For protein expression and purification, E. coli BL21 (DE3) strain was used. This strain carries T7 polymerase gene under control of Lac promoter.

In order to construct the pET22b PelB $6 \mathrm{H} \mathrm{Ag} 43160 \mathrm{~N}$ sfGFP vector, $p E T 22 b$ vector was digested with XhoI (NEB) and NcoI-HF (NEB) enzymes at $37{ }^{\circ} \mathrm{C}$ for $3 \mathrm{~h}$. sfGFP gene was amplified with R3 and R4 primers from the pJT119b plasmid $^{44}$ (kindly gifted by Jeffrey Tabor, Addgene plasmid \#50551). The PCR product was reamplified with R3 and R5 to add TEV recognition site flexible linker to sfGFP coding region. The truncated Ag43 gene was amplified with R1 and $\mathrm{R} 2$ primers from $E$. coli $\mathrm{DH} 5 \alpha$ strain. The isolated DNA pieces were assembled with Gibson Assembly reaction (NEB).

To clone TEVp into pET22b PelB $6 \mathrm{H} \mathrm{Ag} 43160 \mathrm{~N}$ vector, YebF-TEV pZA vector was cut with AflII (NEB) and BamHIHF (NEB) enzymes to obtain TEVp gene. The pET22b PelB $6 \mathrm{H} \mathrm{Ag} 43160 \mathrm{~N}$ sfGFP vector was digested with same restriction enzymes to obtain the vector. The purified DNA products were ligated with $\mathrm{T} 4$ ligation reaction according to manufacturer's instructions.

pZA nTetO PelB 6H Ag43 160N TEV vector was constructed by assembling native TetO promoter, PelB $6 \mathrm{H}$ Ag43 160N TEV gene, and pZA vector. Native TetO promoter was amplified along with TetR repressor from the pdCas9bacteria plasmid $^{45}$ (a gift from Stanley Qi, Addgene plasmid \#44249) using R8 and R9 primers. The PelB 6H Ag43 160N TEV gene was obtained via PCR using R6 and R7 primers. pZA vector was digested with NotI-HF (NEB) and MluI-HF (NEB) restriction enzymes as in conditions described above. The equal molar of each DNA segment was assembled with Gibson Assembly reaction.

mCherry gene was cloned into pET22b PelB 6H Ag43 160N vector. The coding region was amplified from $\mathrm{pZ2}-123$ vector $^{46}$ (a gift from Michael Elowitz, Addgene plasmid \#26598) using R10 and R11 primers. pET22b PelB 6H Ag43 sfGFP $160 \mathrm{~N}$ vector was cut with AflII (NEB) and BamHI-HF (NEB) enzymes. The fragments were purified and assembled with Gibson Assembly.

pET22b PelB 6H Ag43 160N sfGFP-mCherry (registry) vector was constructed. To assemble the vector, $\mathrm{pET} 22 \mathrm{~b}$ PelB $6 \mathrm{H} \mathrm{Ag} 43160 \mathrm{~N}$ sfGFP vector was amplified with R12 and R13 primers. The PelB $6 \mathrm{H} \mathrm{Ag} 43160 \mathrm{~N}$ mCherry coding region was amplified with R14 and R15 primers. The regulatory DNA region was synthesized as gene fragments (Genewiz Inc.). The purified DNA fragments were assembled in Gibson Assembly reaction.

The pZA nTetO BxbI pBAD TP901 PelB 6H Ag43 160N TEV (recombinase) vector was assembled in two steps. In the first step, BxbI pBAD TP901 coding region was amplified from Dual-recombinase-controller plasmid ${ }^{8}$ (a gift from Drew Endy, Addgene plasmid \#44456) using R16 and R17 primers. pZA nTetO plasmid was cut with KpnI-HF (NEB) and MluI-HF 
(NEB). The DNA fragments were purified from agarose gel, and assembled in Gibson Assembly reaction. In the second step, the resulting vector was cut with AvrII (NEB). The PelB $6 \mathrm{H}$ Ag43 160N TEV coding region amplified with R18 and R19 primers. The promoter region was synthesized as gene fragment (Genewiz Inc.). The fragments were assembled with Gibson Assembly.

All PCRs were performed with Q5 polymerase enzyme (NEB) in recommended conditions by the manufacturer. The vector sequences verified with Sanger sequencing (Genewiz Inc.).

Expression and Labeling of Surface Displayed sfGFP and TEVp. Sequence verified pET22b PelB $6 \mathrm{H} \mathrm{Ag} 43160 \mathrm{~N}$ sfGFP or TEVp vector was transformed into E. coli BL21 (DE3) strain with chemical transformation. Single colonies from each plate were picked and inoculated into $5 \mathrm{~mL}$ of $\mathrm{LB}$ medium with appropriate antibiotics. The overnight grown cells were subcultured as $1: 100$ into $10 \mathrm{~mL}$ of fresh $\mathrm{LB}$ supplemented with $\% 1(\mathrm{w} / \mathrm{v})$ glucose and appropriate antibiotics. At mid log phase $\left(\mathrm{OD}_{600}: 0.4-0.6\right)$, the gene was induced with $1 \mathrm{mM}$ isopropyl $\beta$-D-1-thiogalactopyranoside (IPTG) at $18{ }^{\circ} \mathrm{C}$ for overnight.

Induced cells harboring pET22b PelB 6H Ag43 160N sfGFP or TEVp vector was collected in next day. $250 \mu \mathrm{L}$ of cells in $\mathrm{LB}$ medium was centrifuged at maximum speed for $3 \mathrm{~min}$. The pellet was washed with $1 \mathrm{~mL}$ of $1 \times$ PBS once and resuspended in $250 \mu \mathrm{L}$ of $1 \%$ BSA dissolved in $1 \times$ PBS solution. For blocking, cells were incubated at RT for $2 \mathrm{~h}$. Subsequent to incubation, cells were centrifuged at maximum speed for $3 \mathrm{~min}$, and blocking solution was discarded. The cell pellet was resuspended in antihis primary antibody (ThermoFisher Scientific) diluted with 1:250 ratio in \%1 BSA dissolved in $1 \times$ PBS solution and incubated at $4{ }^{\circ} \mathrm{C}$ for overnight. The cells were washed three times with $1 \times$ PBS solution after the incubation. Following the washing step, cells were treated with antimouse secondary antibody conjugated DyLight550 dye (ThermoFisher Scientific) diluted with 1:500 ratio in \%1 BSA dissolved in $1 \times$ PBS solution. The solution was incubated at room temperature for $2 \mathrm{~h}$. The cells were washed two times with $1 \times$ PBS solution. The labeled cells were examined under the epifluorescence microscope (Zeiss).

Trypsin Protease Digestion of Surface-Exposed sfGFP. Prior to trypsin treatment, cells were induced as described above. The freshly induced cells were collected and centrifuged at $8000 \mathrm{~g}$ for $5 \mathrm{~min}$. The supernatant was discarded and suspended in $1 \times$ PBS for further use. For trypsin treatment, $5 \times 10^{8}$ cells were taken and suspended with 200 $\mu \mathrm{L}$ of $1 \times$ PBS. $10 \mu \mathrm{g}$ trypsin protease (Sigma-Aldrich) was added and incubated $37^{\circ} \mathrm{C}$ for $2 \mathrm{~h}$. After incubation, cells were centrifuged and washed twice with $1 \times$ PBS. The washed cells were resuspended in $200 \mu \mathrm{L}$ of $1 \times$ PBS. The fluorescence emission of cells was measured with the M5 spectrophotometer (Molecular Devices).

Heat Release of Surface Displayed sfGFP and TEVp. To release surface displayed proteins (either TEV or sfGFP), 5 $\times 10^{8}$ cells were taken and suspended with $200 \mu \mathrm{L}$ of $1 \times$ PBS. The suspended cells were briefly heated at $60{ }^{\circ} \mathrm{C}$ for $5 \mathrm{~min}$. Following the heat shock, cells were immediately centrifuged at maximum speed for $5 \mathrm{~min}$. The supernatants were collected for further analysis. For sfGFP displaying cells, the fluorescence emission of supernatants was measured with the M5 spectrophotometer. Western blot analysis was performed to verify the presence of sfGFP and TEVp fused with truncated passenger domain of $\mathrm{Ag} 43$.

Biochemical Release of Surface Displayed sfGFP with TEVp and TEVp Activity in Different Growth Media. $5 \times$ $10^{8}$ fresh sfGFP displayed cells, which were induced as described above, were centrifuged and washed with TEVp buffer ( $50 \mathrm{mM}$ Tris- $\mathrm{HCl} \mathrm{pH}=8,0.5 \mathrm{mM}$ EDTA) without DTT. Cells were resuspended in $200 \mu \mathrm{L}$ of TEVp buffer, and approximately $6 \mu \mathrm{g}$ of GST-TEVp was added. The cleavage reaction was incubated at $4{ }^{\circ} \mathrm{C}$ for overnight. Cells were centrifuged at full speed for $5 \mathrm{~min}$. Supernatants were collected. The pellets were resuspended in $200 \mu \mathrm{L}$ of PBS. The fluorescence emissions of collected supernatants and resuspended cells were measured with the M5 spectrophotometer. For fluorescence microscopy and flow cytometer analysis, cells were labeled the same as described above.

To assess the activity of TEVp in different media, $400 \mu \mathrm{L}$ of fresh sfGFP displayed cells which were induced as described above was taken and centrifuged at maximum speed for $5 \mathrm{~min}$. The cell pellets were washed twice with either LB or M63 defined medium or MOPS defined medium. After washing, cells were resuspended in different growth media in different $\mathrm{pH}$. LB $(\mathrm{pH}=5.2,7.0,8.2)$, M63 defined media $(\mathrm{pH}=5.2$, 6.0, 7.0, 8.2), and MOPS defined media ( $\mathrm{pH}=5.2,6.0,7.0$, 8.2) was used. $6 \mu \mathrm{g}$ of GST-TEVp was added into suspended cells then incubated at $4{ }^{\circ} \mathrm{C}$ for overnight. Following the incubation, cells were centrifuged at maximum speed for $5 \mathrm{~min}$. The fluorescence emissions of collected supernatants were measured with the M5 spectrophotometer.

Protein Precipitation and Western Blotting. Western blot analysis was performed after heat and biochemical release of surface displayed proteins to verify their presence in supernatants. The proteins were precipitated from the supernatant using acetone. Five volume of acetone was added into supernatants to precipitate proteins. The solutions were incubated at $-20{ }^{\circ} \mathrm{C}$ for overnight. The precipitated proteins were centrifuged at maximum speed, $4{ }^{\circ} \mathrm{C}$ for $1 \mathrm{~h}$. The solution was discarded and protein pellet was air-dried. The pellets were not over dried in this process otherwise it is hard to resuspend. The pellets were dissolved in $1 \times$ SDS-PAGE loading dye following the drying.

The dissolved samples were run in SDS-PAGE gel. The proteins were blotted onto PVDF membrane via Trans-Blot Turbo (Bio-Rad) as manufacturer's instructions. Subsequently, the membrane was blocked in 5\% milk powder. The membrane was incubated for overnight in 1:5000 diluted antihis primary antibody (ThermoFisher Scientific) following the blocking. The membrane was washed with TBST buffer twice for $10 \mathrm{~min}$ and once for $5 \mathrm{~min}$. The membrane was incubated in 1:10000 diluted antimouse secondary antibody conjugated with horseradish peroxidase (Abcam). The membrane was washed same as above. The membrane was treated with luminescence substrate kit (Bio-Rad) and visualized with ChemiDoc Imaging System (Bio-Rad).

Molecular Modeling of TEVp-Ag43 160N Fusion. The $3 \mathrm{D}$ structure of TEV-protease-truncated passenger domain fusion protein was predicted with I-Tasser. The protein sequence without pelB secretion tag was uploaded to https://zhanglab.ccmb.med.umich.edu/I-TASSER/ Web site in default mode. One of the predicted 5 protein structure was selected to align with native TEVp structure with PyMol protein structure alignment tool. 
a)

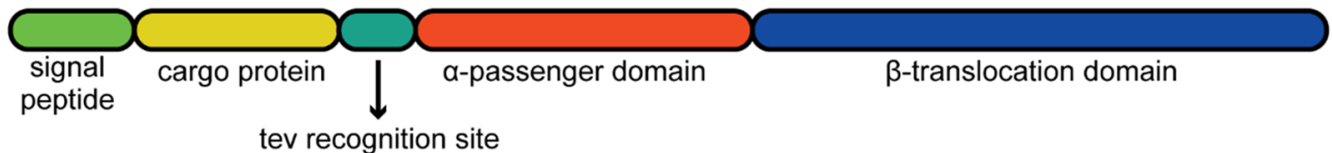

b)

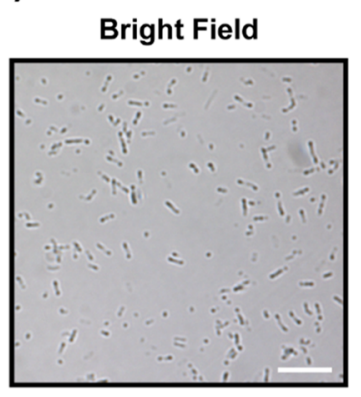

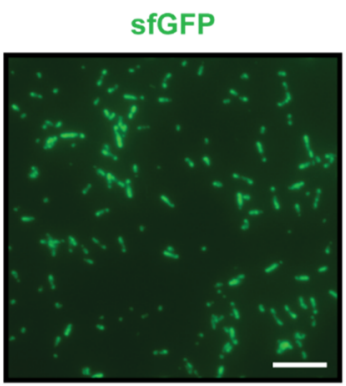

c)

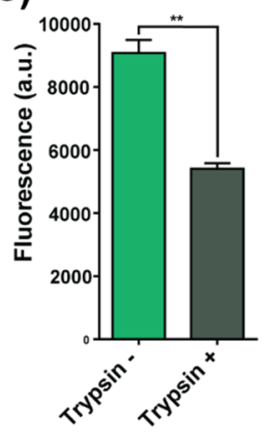

Figure 1. sfGFP can be displayed on cell surface upon induction of display cassette. (a) Topology of engineered Ag43 gene for protein display. (b) Immunostaining of cells expressing the display cassette with antihis antibody conjugated with Dylight 550 (white bars represent $10 \mu \mathrm{m}$ ). (c) Fluorescence of induced cells after trypsin protease accessibility assay. The whole fluorescence was normalized by dividing with $\mathrm{OD}_{600}$. The assay was performed in triplicates, and statistical significance was determined with Student's $t$ test. $(* * p<0.01)$.

Coexpression of Ag43 160N sfGFP and TEVp and Release Kinetics. pET22b PelB $6 \mathrm{H} \mathrm{Ag} 43160 \mathrm{~N}$ sfGFP and pZA nTetO PelB $6 \mathrm{H}$ Ag43 160N TEV vectors were cotransformed sequentially into E. coli BL21 (DE3) strain with chemical transformation. A single colony was picked from the agar plate and grown for overnight in LB with appropriate antibiotics. The cells inoculated in modified MOPS defined medium ( $80 \mathrm{mM}$ MOPS, $\mathrm{pH}=8.2$ ) with 1:100 dilution, and grown at $37{ }^{\circ} \mathrm{C}, 200 \mathrm{rpm}$ until OD600 reached to 0.4 . The cells were induced with IPTG and anhydrotetracycline (aTc). The induced cells were grown at $18{ }^{\circ} \mathrm{C}, 200 \mathrm{rpm}$ for overnight. In the next day, cells were collected and centrifuged at maximum speed for $5 \mathrm{~min}$. The fluorescence emission of supernatants was measured with the M5 spectrophotometer. Fluorescence signal of blank solution and empty cell's supernatant were subtracted from measured supernatant fluorescence signals of uninduced and induced cells.

To find release kinetics upon TEVp display, the freshly induced cells were centrifuged at $3000 \mathrm{rpm}$ for $10 \mathrm{~min}$. The medium of cells was changed while the inducer conditions remained constant. The cells were incubated at $18{ }^{\circ} \mathrm{C}, 200$ $\mathrm{rpm}$. In every $4 \mathrm{~h}, 400 \mu \mathrm{L}$ of cells were taken and centrifuged at maximum speed for $5 \mathrm{~min}$. The supernatants were taken for fluorescence measurement. The remaining pellets were resuspended in $1 \times$ PBS for whole fluorescence measurements. All fluorescence measurements were performed with the M5 spectrophotometer.

Sequential Secretion of mCherry and sfGFP. The sequence verified registry and recombinase vectors were cotransformed into DH5 $\alpha$ PRO strain. A single colony from cotransformation plate was grown for overnight in $\mathrm{LB}$ with appropriate antibiotics and $1 \%$ glucose. Cells were diluted at 1:250 into modified MOPS medium with $250 \mathrm{ng} / \mu \mathrm{L}$ aTc, appropriate antibiotics and $1 \%$ glucose. The cells were induced for $24 \mathrm{~h}$ at $30^{\circ} \mathrm{C}$. After the induction, cells were centrifuged at $1000 \mathrm{~g}$ for $10 \mathrm{~min}$ and washed twice with fresh MOPS medium. Washed cells were diluted to $0.3 \mathrm{OD}_{600}$, and grown for $24 \mathrm{~h}$ at $18{ }^{\circ} \mathrm{C}$. Following the growth, the supernatants were collected and mCherry fluorescence was measured with M5 spectrophotometer (Ex/Em: 544/612 nm, $570 \mathrm{~nm}$ cutoff). Meanwhile, grown cells were diluted at 1:250 ratio into fresh modified MOPS medium with $0.2 \%$ arabinose, appropriate antibiotics and $0.2 \%$ glucose, and induced at $30{ }^{\circ} \mathrm{C}$ for $24 \mathrm{~h}$. Subsequent to induction, cells were centrifuged, washed, and rediluted the same as described above. The diluted cells were grown at 30 ${ }^{\circ} \mathrm{C}$ for $24 \mathrm{~h}$. In the next day, supernatant were collected and sfGFP fluorescence was measured with M5 spectrophotometer (Ex/Em: 488/532 nm, $510 \mathrm{~nm}$ cutoff). Fluorescence of blank solution and empty cell supernatant were subtracted from measured fluorescence signals.

Statistical Analysis. The data in column graphics were obtained from triplicate experiments. All of the column data are presented as mean \pm standard deviation. The Student's $t$ test with Welch correction or one-way ANOVA were used for assessing the significances. GraphPad Prism v6 was used for visualization and statistical analysis.

\section{RESULTS AND DISCUSSION}

Cell Surface Display of sfGFP via Ag43 Autotransporter Protein. The native E. coli autotransporter protein, $\mathrm{Ag} 43$, is engineered to display POI on cell surface. The Ag43 protein consists of an $\alpha$-passenger domain, a $\beta$-translocation domain, and an $\mathrm{N}$-terminal signal sequence (Figure S1). ${ }^{47}$ During the secretion, the $\alpha$-domain is cleaved by internal protease motif, and remains attached to the cell surface by noncovalent interactions. The $\alpha$-domain has an L-shaped $\beta$ helical structure and promotes aggregation of bacterial cells via self-recognition. Biochemical and structural studies show that residues $1-160$ amino acid region at $\mathrm{N}$-terminal (the first amino acid of $\alpha$-passenger domain is considered as 1) is required for self-recognition. ${ }^{47}$ Therefore, we replaced the first 160 amino acids of the $\alpha$-passenger domain with cargo proteins (Figure 1a).

His-tagged super folder green fluorescent protein (sfGFP) is selected as first cargo protein to be displayed on cell surface to characterize the display cassette. The expression and display of sfGFP on the bacterial surface is evaluated with fluorescence microscope. Displayed his-tagged sfGFP molecules on cells were labeled with antibody specific to his-tag in the absence of membrane solubilizing agents. Accessibility of His specific 
a)

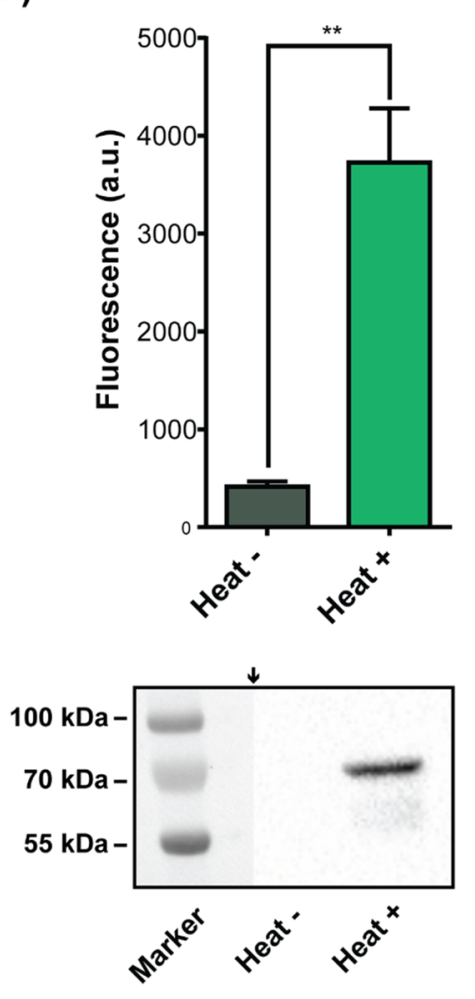

b)
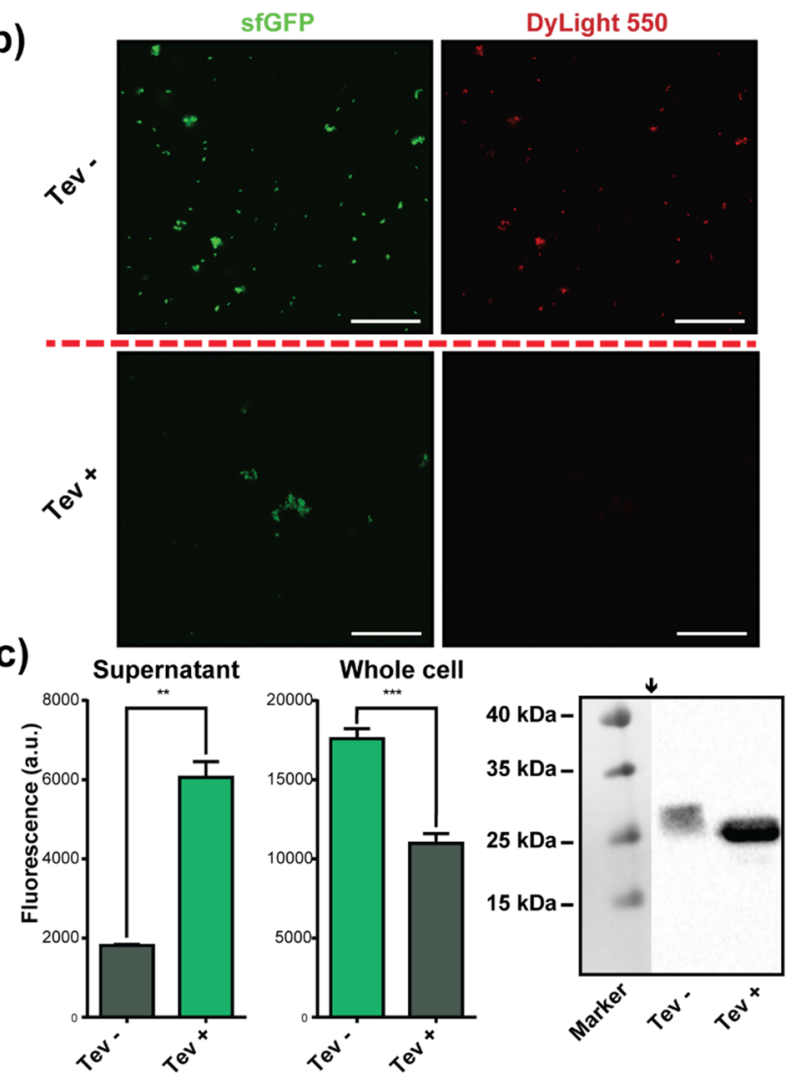

Figure 2. Displayed sfGFP molecules can be released to extracellular environment via physical and biochemical inputs. (a) Fluorescence measurements from cell supernatants after heat shock. The experiments were performed in triplicates, and statistical significance was determined with Student's $t$ test. ( $\left.* *_{p}<0.01\right)$. Presence of sfGFP following the heat shock was verified with Western blotting. Expected band for sfGFPtruncated $\alpha$-domain fusion is $63.4 \mathrm{kDa}$. The marker and samples were run in the same SDS gel, and they are sliced to put them together for clear view. (b) Immunostaining of induced cells treated $\mathrm{TEVp}$ in the absence of any membrane solubilizing agents (white bars represent $40 \mu \mathrm{m}$ ). (c) The whole cell and supernatant fluorescence after TEVp addition. The whole fluorescence was normalized by dividing OD 600 . The experiments were performed in triplicates and statistical significance was determined with Student's $t$ test. (**p $<0.01$, and $* * * p<0.001$ ). Presence of sfGFP molecules after TEVp treatment was verified with Western blotting $(25 \mathrm{kDa})$. The marker and samples were run in the same SDS gel and they are sliced to put them together for clear view.

antibodies conjugated with DyLight550 to His-tag indicates the exposition of sfGFP on the cell surface (Figure $1 \mathrm{~b}$ ).

We further confirmed the localization of sfGFP on cell surface with trypsin protease accessibility assay. The extracellularly exposed protein can be digested with trypsin protease. Treating induced cells with trypsin protease led to significant decrease in whole cell fluorescence, yet the fluorescence signal did not completely disappear after digestion reaction (Figure 1c). As the localization and secretion of the $\alpha$ domain requires multiple steps, some of expressed sfGFP proteins were not displayed and were inaccessible to trypsin protease. The comparison of the signals from immunofluorescence images indicates the same conclusion with trypsin digestion assay. Not all the sfGFP expressing cells were labeled with anti-His antibody, and there is heterogeneity in the cell population based on displaying the cargo protein.

Release of Surface Displayed Proteins. The noncovalent interaction between $\alpha$ and $\beta$ domains of Ag43 autotransporter protein can be broken with heat treatment. ${ }^{47,48}$ Hence, release of the cargo protein fused with $\alpha$-domain can be accomplished with brief heat shock. To release the cargo protein, we briefly heated the induced cells. The cells were immediately centrifuged after heat shock and supernatants were collected. A significant increase in green fluorescence obtained from the supernatant of heat shocked cells compared to nontreated cells indicates that $\alpha$-domain fused with sfGFP is released subsequent to heat shock (Figure 2a). The presence of sfGFP $(25 \mathrm{kDa})$ fused with $\alpha$-domain $(45 \mathrm{kDa})$ in the supernatant was verified with Western blotting (Figure 2a). Moreover, cells were visualized under light microscope subsequent to heat treatment. The microscope images revealed that cells were intact after the treatment (Figure S2). Protein release from cell surface can be controlled with different physical parameters in addition to temperature as the noncovalent interactions can be disturbed with changing various physical properties such as ionic strength. ${ }^{49}$ However, cargo proteins are secreted to extracellular medium covalently attached to $\alpha$-passenger domain in this release system. The activity and folding of cargo proteins might be affected because of remaining additional large protein domains. ${ }^{50-52}$

Sequence specific proteases such as TEVp can be displayed to cleave cargo proteins off from the cell surface biochemically via introducing a cleavage recognition sequence to the cargo protein. The cleavage of recognition sequence leads to release of the cargo protein to extracellular medium with only remnants of cleavage site attached to cargo protein while $\alpha$ passenger domain remains attached to cell surface. To test this hypothesis, we inserted TEV cleavage site (ENLYFQ/G) with a flexible linker (GGGGS) between the $\alpha$-passenger domain and sfGFP. The flexible linker is inserted to ensure the 


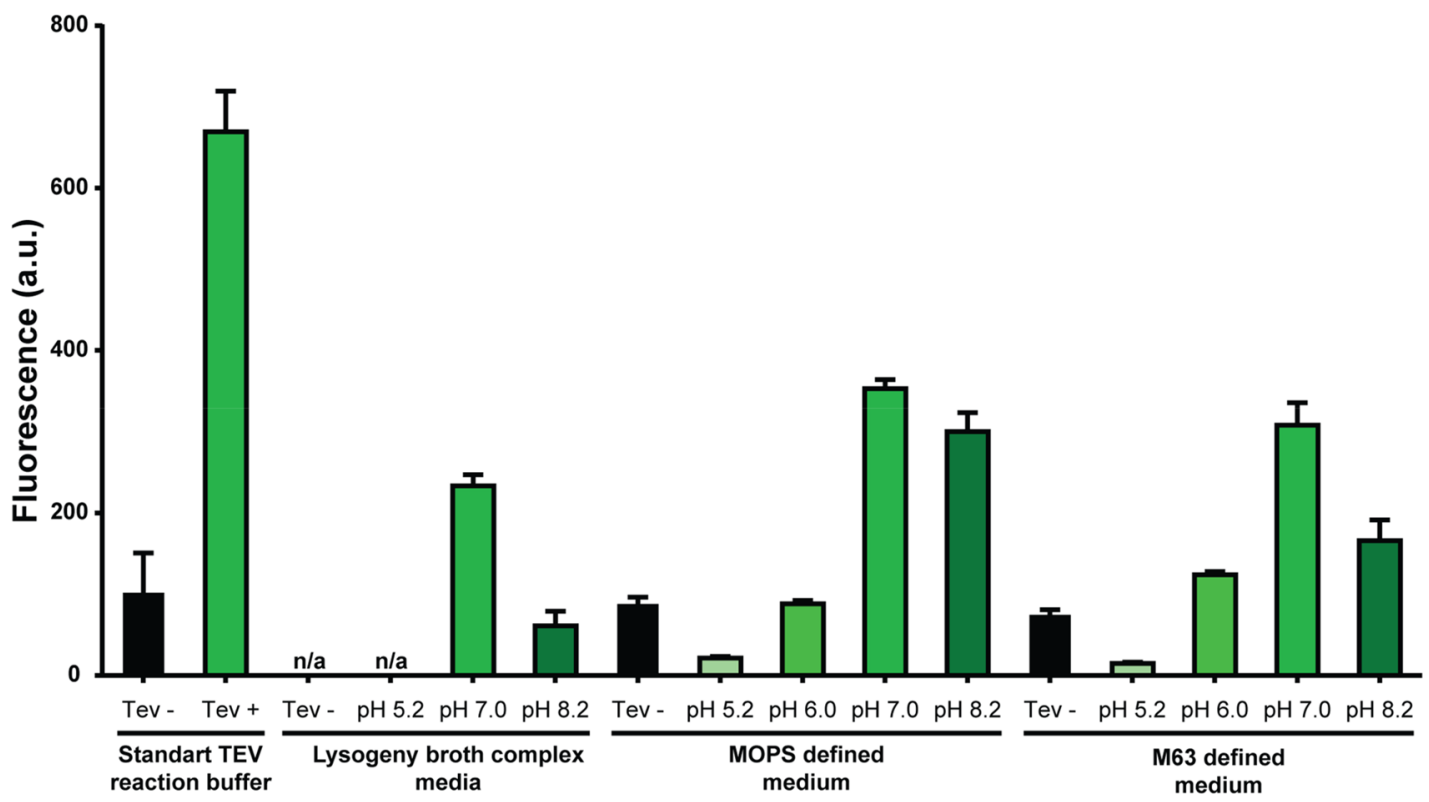

Figure 3. TEVp activity in LB complex medium at $\mathrm{pH}$ equals to 5.2, 7, and 8.2, MOPS defined medium at $\mathrm{pH}$ equals to 5.2, 6.0, 7.0, and 8.2, and M63 defined medium at $\mathrm{pH}$ equals to 5.2, 6.0, 7.0, and 8.2.

accessibility of TEVp to its recognition site. Cells harboring the display plasmid, composed of sfGFP with TEV recognition site, were induced and then were treated with purified TEVp in standard reaction buffer following the induction. After the treatment, cells were centrifuged and supernatants were collected. Anti-His antibodies were used to label the cells following the treatment without membrane solubilizing agents. The loss of immunostaining signal upon TEVp treatment suggested that the sfGFP was cleaved off from cell surface (Figure 2b). The signal loss also was confirmed quantitatively with flow cytometer. Percentage of cells that were expressing sfGFP and labeled with DyLight 550 conjugated antibody decreased by 3 -folds in the cell population following the TEVp treatment (Figure S3). Moreover, the whole cell green fluorescence was significantly decreased upon incubating cells with TEVp as expected (Figure 2c). To confirm the decrease in whole cell fluorescence was not caused by random degradation of sfGFP molecules, supernatant fluorescence after the TEVp reaction was also measured. A dramatic increase in green fluorescence of the supernatant obtained from TEVp treated cells was verified that GFP molecules were not randomly degraded and they were still fluorescent (Figure 2c). In addition, we showed that cleaved sfGFP products (25 $\mathrm{kDa}$ ) were present in the supernatant by Western blotting (Figure 2c). On the basis of our observations, the inserted TEV recognition site is accessible to TEVp, and can be cleaved in standard reaction buffer, while the cargo protein, sfGFP, is retaining its functional structure.

Cleavage of Displayed Protein with TEVp in Different Growth Media. Prior to codisplay the TEVp with sfGFP, the activity of TEVp was determined in common E. coli growth media including Lysogeny Broth (LB) complex medium, MOPS defined medium and M63 medium with different $\mathrm{pH}$ values. The reason behind this, mixture of different ions to support the bacterial growth might have a negative effect on the protease activity. Indeed, previous report showed that TEVp can be inhibited by $\mathrm{Zn}^{2+}$ ions at concentrations greater than $5 \mathrm{mM}$ and by agents causing oxidation of cysteine. ${ }^{53} \mathrm{In}$ addition, there is no information about the effect of other divalent ions on TEVp activity such as $\mathrm{Mg}^{2+}$, which is required for cell wall integrity of $E$. coli. ${ }^{54}$ We developed a quick assay to determine relative TEVp activity in different conditions via using sfGFP displaying cells. sfGFP was displayed with TEVp recognition site on the cell surface. Then, sfGFP displayed cells were treated with TEVp for overnight in different media at $\mathrm{pH}$ ranging from 5.2 to 8.2 (Figure 3 ). The fluorescence of supernatants was measured and compared after the cleavage reaction. Maximum cleavage rate was observed at $\mathrm{pH} 7$ for all media. However, decrease or increase in $\mathrm{pH}$ of $\mathrm{LB}$ dramatically reduces the activity of TEVp. Complex content of LB due to the yeast extract may negatively affect the activity. For both M63 and MOPS defined medium, decreasing $\mathrm{pH}$ resulted in a drastic decrease in amount of cleaved product as a function of sfGFP fluorescence whereas increasing $\mathrm{pH}$ to 8.2 has a modest effect. Cleavage in MOPS defined medium at $\mathrm{pH} 7$ has highest reaction rate compared to other media and conditions. Considering the acetic acid formation in the presence of glucose by $E$. coli, the $\mathrm{pH}$ of medium will decrease continuously during the growth. ${ }^{55}$ Therefore, we modified MOPS defined medium. The concentration of buffering agent in media, MOPS, was increased to $80 \mathrm{mM}$ and the initial $\mathrm{pH}$ of media was adjusted to 8.2 .

Codisplay of TEVp and sfGFP on the Cell Surface for Controlled Release. We predicted the 3D structure of fusion protein (truncated $\alpha$-passenger domain fused with TEVp) using I-Tasser server, ${ }^{56-58}$ as folding of TEVp might be affected by truncated $\alpha$-passenger domain. The predicted 3D structure was in good agreement with native structure of TEVp as well as truncated $\alpha$-passenger domain (Figure S4a,b). Moreover, the catalytic cleft of TEVp seems not to be affected by fusion with truncated $\alpha$-passenger domain (Figure S4c). We replaced the cargo protein with TEVp to display on the cell surface. For initial characterization of newly formed display cassette with TEVp, we performed immunostaining and Western blot analysis. Results showed that TEVp is successfully displayed on cell surface and released after heat treatment (Figure S4d,e). 

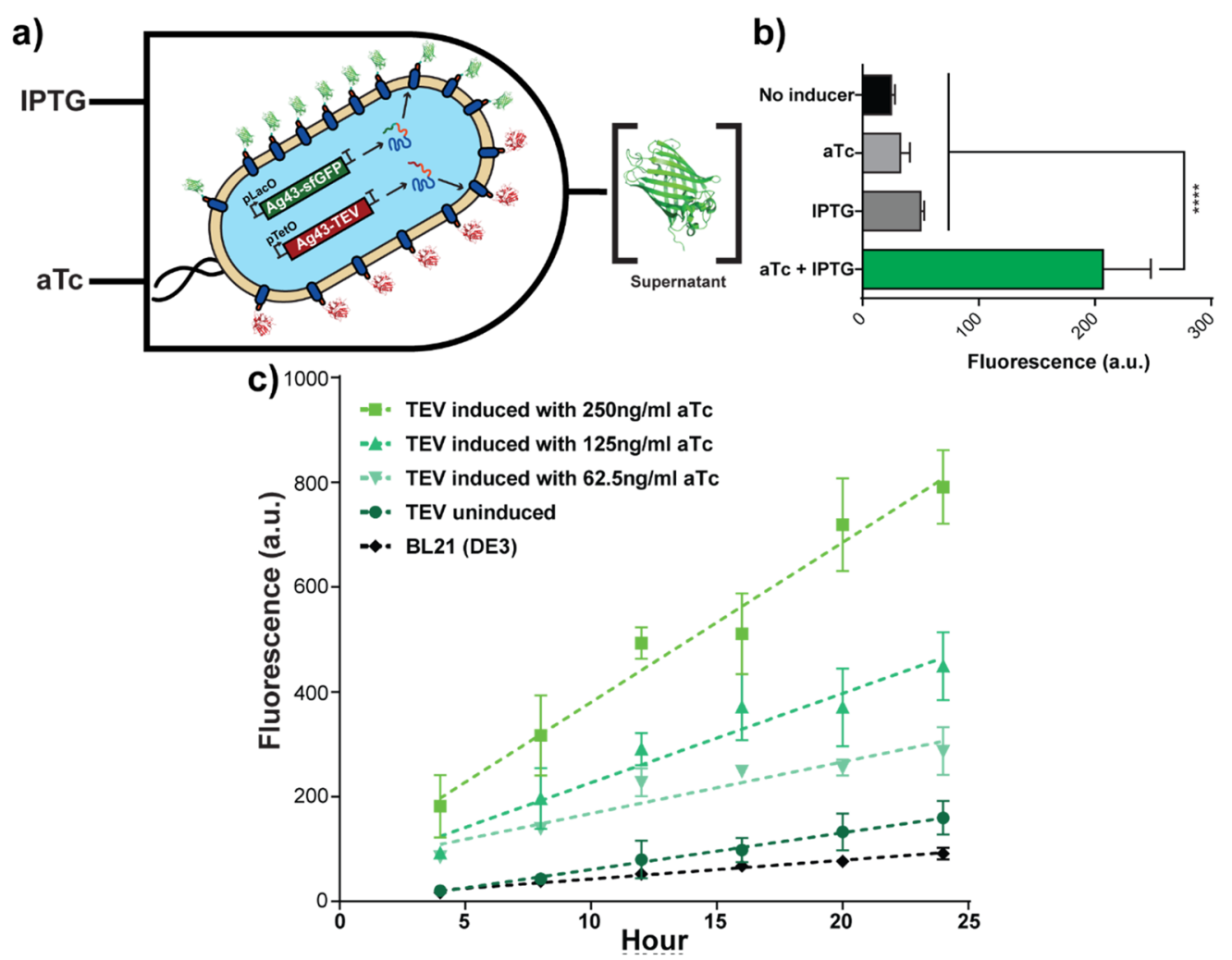

b)

luorescence (a.u.)

Figure 4. Coinduction of sfGFP and TEVp carrying display cassette leads to secretion of displayed sfGFP molecules to extracellular environment. (a) Schematic representation of the constructed AND gate to test the system. Output signal of the AND gate is the increase in supernatant fluorescence. Induction of both TEVp and sfGFP is required to release the sfGFP molecules to extracellular environment. (b) Supernatant fluorescence of cells induced with only aTc or only IPTG or both of them. Fluorescence of supernatants obtained from uninduced cells was also measured. The supernatant fluorescence of empty cells was subtracted from measured fluorescence values. Experiments were performed in triplicates, and statistical significance was determined with student's test $(* * * p<0.001)$. (c) Protein release kinetic of the genetic circuit. Cells carrying the circuit plasmids were induced with $1 \mathrm{mM}$ IPTG and different aTc concentrations. The fluorescence signal was obtained from supernatant of empty cells, uninduced cells, and cells induced at different aTc concentrations $(62.5,125$, and $250 \mathrm{ng} / \mathrm{mL}) \mathrm{for} 24 \mathrm{~h}$ with $4 \mathrm{~h}$ intervals.

To test the sfGFP release upon TEVp display, we constructed an AND gate between sfGFP and TEVp display systems. TEVp display cassette was cloned downstream of aTc inducible promoter in p15A origin plasmid, while sfGFP display cassette was kept downstream of IPTG inducible promoter in ColE1 origin plasmid. After induction of cotransformed cells, 4-fold increase was observed in the supernatant of IPTG and aTc induced cells compared to supernatants of uninduced, aTc only induced, and IPTG only induced cells (Figure $4 a$ and $4 b$ ). The release of sfGFP molecules upon the codisplay of TEVp can be explained asymmetric distribution of cell wall and membrane proteins during bacterial cell division. In recent report, polar localization of some membrane proteins was shown. ${ }^{59}$ Indeed, we observed that displayed sfGFP proteins accumulated at polar edges of E. coli membrane (Figure S5). On the basis of the report and our observation, we think that the TEV protease is concentrated around sfGFP and able to cleave the recognition site because of the accumulation of displayed proteins at the poles of the cell surface after certain number of cell divisions.

We characterized the release kinetics of the genetic circuit over time by inducing cells with varying concentrations of IPTG and aTc. The cells were grown until $0.4 \mathrm{OD}_{600}$, and then they were either induced with only IPTG (labeled as TEV uninduced) or both IPTG and aTc (labeled as TEV induced with 250,125 , and $62.5 \mathrm{ng} / \mathrm{mL}$ aTc) for overnight. The growth media was refreshed while induction conditions were kept same for the next day, and fluorescence emission of cell supernatant was monitored for $24 \mathrm{~h}$. In Figure $4 \mathrm{c}$ the kinetics (detected from proteins in supernatant) of the protein release for different cell setting is presented. A linear regression was done to calculate the slope for each case to represent the initial release kinetics of the proteins as a function of aTc concentrations. The equations for fitted lines, $R^{2}$, and fluorescence increase rate values were given in Table S2. The green fluorescence of empty cell's supernatant increased gradually as expected because it is reported that E. coli cells secrete green fluorescent molecules such as FMN, FAD, and riboflavin to media during the growth. ${ }^{60}$ Meanwhile, the fluorescence change of uninduced cell's supernatant indicated that system has a little but insignificant leakage compared to empty cells. Induction of cells with aTc led to increase in supernatant fluorescence compared to uninduced cells (Figure $4 c)$. Furthermore, the fluorescence increase rate has changed on the basis of the aTc concentration. Addition of higher concentrations of aTc provided increase in fluorescence increase rate (Table S4). Hence, the amount of released sfGFP molecules can be tuned with adjusting the amount of displayed TEVp on cell surface.

There are several strategies developed in Gram-negative bacteria to secrete recombinant proteins, yet they halt cellular growth either by requiring large gene clusters (TI-SS and TIII- 
a)
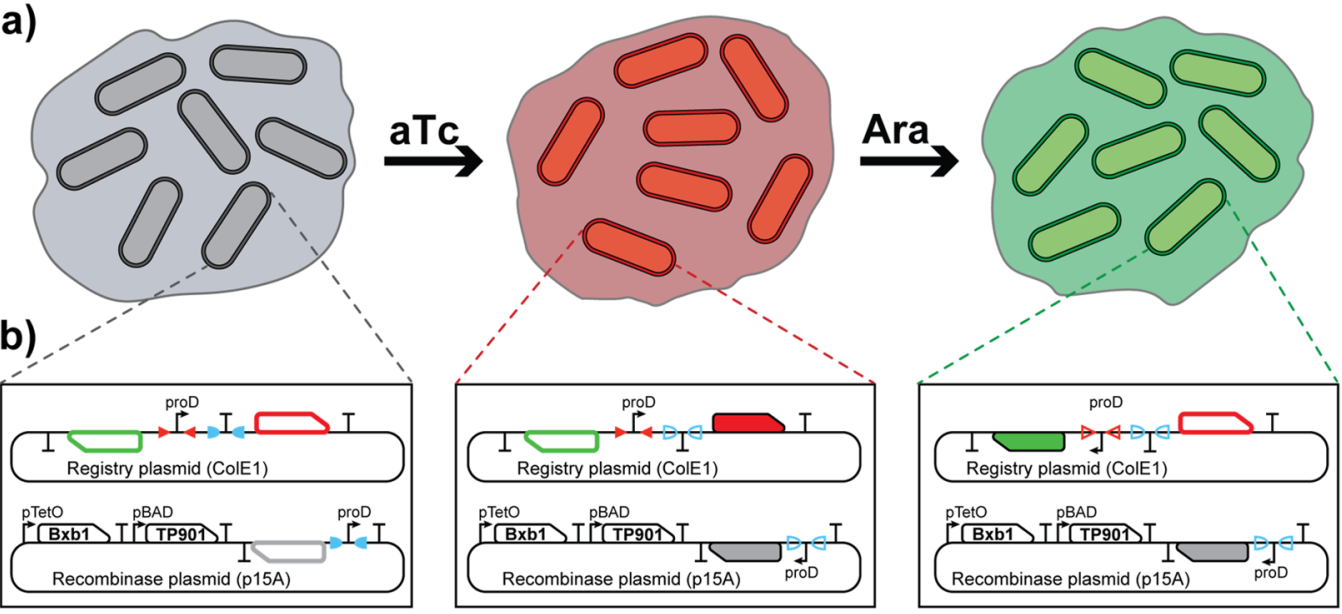

D U Unrecombined Bxb1 site $\triangle \triangleleft$ Unrecombined TP901 site

sfGFP display cassette

$\longrightarrow$ Expressed
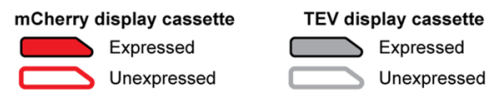

c)

mCherry Release

sfGFP Release
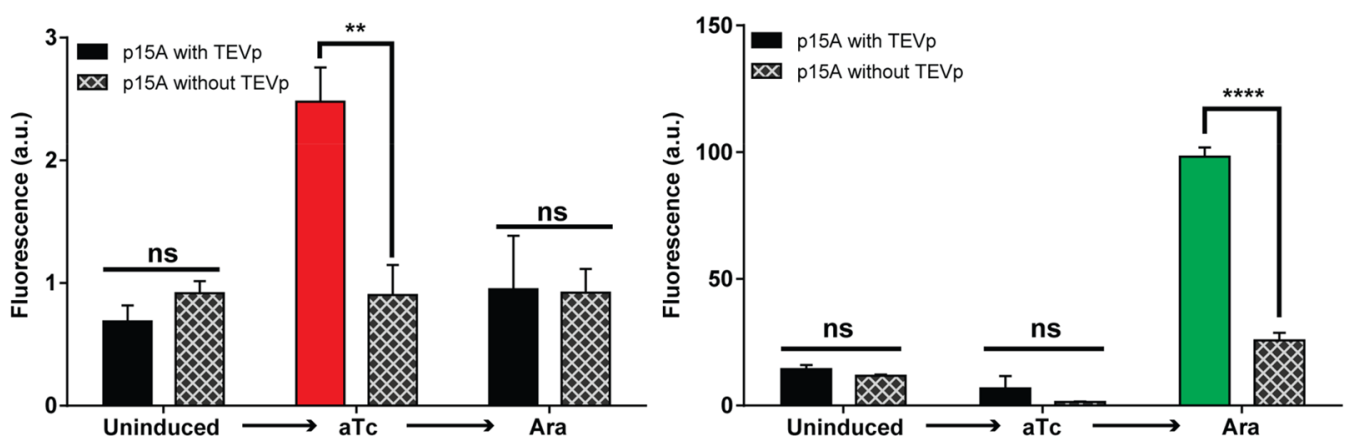

Figure 5. Display-release system can be engineered to secrete multiple proteins in a defined order. (a) Schematic presentation of sequential protein display and release upon receiving chemical input in a sequence of aTc to Ara. (b) Representation of each biological state for each induction condition of a $\mathrm{Tc}$ to Ara sequence. In the uninduced state, transcription from proD promoter is blocked by unidirectional transcription terminator, and none of the display cassettes are transcribed. Following the aTc induction, BxbI will be produced and will invert the terminator in regulatory DNA region in the registry plasmid and proD promoter at the upstream of the TEVp display cassette. The inversion enables the production of mCherry and TEVp display cassettes. Coproduction of those genes results in the release of mCherry. Addition of Ara will change the biological state as it triggers the production TP901. TP901 recombinase inverts the proD promoter, which enables production of sfGFP display cassette while shutting the production of mCherry display cassette down. As sfGFP and TEVp display cassette are coproduced in the new states, sfGFP will be released from the cells instead of the mCherry. (c) Red (left) and green (right) supernatant fluorescence of cells that either contain p15A with TEVp or p15A without TEVp with ordered induction (aTc to Ara). The supernatant fluorescence of empty cells was subtracted from measured fluorescence values. The experiments were performed in triplicates, and statistical significance was determined with two-way ANOVA (** $p<0.01$, $* * * * p<0.0001)$.

SS) or expressing toxic genes to induce outer membrane leakiness. $^{61}$ Moreover, none of the engineered secretion systems achieve the tagless secretion. Our strategy yields considerable amounts of secreted proteins without any functional tags. Moreover, the amount of released protein in media can be tuned by changing the amount of displayed TEVp on cell surface. In addition, the self-secretory nature of autotransporter proteins make the engineered secretion system cheap in terms of protein production economy of the cells compared to TI-SS and TIII-SS. Hence, we believe that the engineered display-release system can be implemented in complex genetic circuits to perform sophisticated works due to its simplicity.

Sequential Secretion of Multiple Proteins. As a proofof-concept, we utilized the system for secretion of multiple proteins in a defined order. We used recombinase based state machines that is described previously in bacterial cells to define stable states. ${ }^{16}$ Although there are other circuitries available to define stable states in cells such as toggle switch, ${ }^{62}$ the necessity of additional transcription factors will cause additional metabolic load on cells. In recombinase-based systems, the expression of recombinase proteins can be switched off to reduce the extra burden on the cell metabolism. Additionally, the output signals can be tuned by changing the order of the inputs.

The cells were engineered to secrete two different fluorescence proteins red and green in a sequence upon ordered exposure of two inducers, aTc, and Ara. The exposure of inducers with aTc to Ara order will be resulted in release of fluorescence proteins with red-to-green order (Figure 5a). The sequence of fluorescent protein release was established with stable biological states defined in the registry plasmid based on the state of regulatory DNA region. 
In our system, the registry plasmid has high copy number in cells (ColE1 origin), and composed of mCherry and sfGFP display cassettes facing opposite direction, and regulatory DNA region that controls the expression of display cassettes. The regulatory DNA region in the registry plasmid is located between display cassettes, and contains proD promoter ${ }^{63}$ between antialigned TP901 attB-attP sites and a unidirectional terminator (secG-Leu) ${ }^{64}$ between antialigned BxbI attB-attP sites following the proD promoter. The recombinase coding plasmid contains two large serine recombinases: BxbI under control of the pBAD promoter and TP901 under control of the pTetO promoter. Moreover, the plasmid includes TEVp display cassette under control of the proD promoter yet promoter placed in reverse direction between antialigned BxbI attB-attP sites to eliminate unnecessary transcription in uninduced state (Figure $5 \mathrm{~b}$ ).

To test the system, we constructed a display cassette for mCherry and verified the display of mCherry on the cell surface with trypsin accessibility assay (Figure S6). Moreover, release of displayed mCherry with heat shock and with TEVp treatment were shown (Figure S7). Subsequent to verification and release of mCherry, registry and recombinase plasmids were constructed. The plasmids were cotransformed in E. coli DH5 $\alpha$ PRO strain because transformation of recombinase plasmid into BL21(DE3) strain failed repetitively. Transformed cells were induced with aTc. Following the induction, cells were washed with fresh media to remove residual inducer for switching off the recombinase expression. Afterward, cells were suspended and diluted in fresh media. Supernatant fluorescence of mCherry and sfGFP were recorded from overnight grown cells. Red fluorescence of the supernatant from $\mathrm{p} 15 \mathrm{~A}-\mathrm{TEV} \mathrm{p}$ plasmid carrying cells was significantly increased compared to the control groups (supernatant fluorescence of uninduced cells and induced cells that are carrying the p15A plasmid without TEVp). Green fluorescence of the supernatant from aTc induced cells remained unchanged. An increase in fluorescent signal indicates that mCherry proteins were released to extracellular medium in the absence of any inducer. The cells were switched to mCherry releasing state upon expression of the Bxb1 (Figure 5c). The mCherry releasing cells were induced with Ara the same as described above. Following the overnight growth, green supernatant fluorescence was increased significantly compared to control groups. Meanwhile, red supernatant fluorescence of Ara induced cells was decreased to the level of uninduced cells. The increase in green supernatant fluorescence and decrease in red supernatant fluorescence indicates that cells were switched from the mCherry releasing state to sfGFP releasing state following the Ara induction (Figure 5c). Cells can stay in a stable state as long as registry plasmid persists in the cells. The order of addition of aTc and Ara, indeed, provide sequential secretion of fluorescence proteins from red to green.

\section{CONCLUSION}

In this study, we have developed a protein release system that can be utilized in engineering of efficient synthetic microbial cells in various applications such as targeted drug delivery, production of protein-based drugs at point-of-need, biomaterial production, and whole cell biocatalysts. Currently engineered protein secretion systems either are expensive in terms of cellular energy or slow down the cellular growth. Furthermore, the secretion tag remains covalently attached to POI in most of the cases. To overcome these obstacles, native ability of autotransporters in protein translocation through extracellular space was engineered to display a reporter protein on the cell surface. The release of displayed fluorescent protein was accomplished with codisplaying a site-specific protease, TEVp. As the protein display and release are controlled by two distinct protein expression cassettes, they can be controlled with chemical signals though inducible promoters. We constructed a simple two-input one-output AND gate to prove that a robust system for controlled protein release is possible; however, it is possible to build more complex logic operations using additional elements. On the basis of our preliminary observations, the amount of released protein can be tuned by controlling the amount of displayed TEVp on the cell surface.

In addition, we built a synthetic bacterium by using the developed strategy that is able to release multiple proteins in a sequence response to chemical inputs. Using a regulatory DNA element that controls the expression of two different protein display cassettes, two different release states were defined in the engineered bacterium. Upon receiving the chemical signals in the right order, engineered bacteria released mCherry and sfGFP molecules sequentially or could release and display sfGFP molecules. We anticipate that genetically controlled protein release systems will improve the performance of synthetic microorganisms. In our opinion, releasing multiple proteins in defined sequence will pave the way for applications of the synthetic microorganisms in different fields such as probiotic engineering and cell-based therapies for complex diseases.

\section{ASSOCIATED CONTENT}

\section{S Supporting Information}

The Supporting Information is available free of charge on the ACS Publications website at DOI: 10.1021/acssynbio. 9 b00062.

Supporting figures and tables (PDF)

\section{AUTHOR INFORMATION}

\section{Corresponding Author}

*E-mail: urartu@bilkent.edu.tr.

ORCID $\odot$

Urartu Özgür Şafak Şeker: 0000-0002-5272-1876

Author Contributions

UOSS conceived the idea. UOSS and REA designed the experiments. REA, BMK, and BS carried out the experiments. UOSS and REA discussed the results and wrote the manuscript. All of the authors have read and approved the manuscript.

\section{Notes}

The authors declare no competing financial interest.

\section{ACKNOWLEDGMENTS}

This study was supported by TUBITAK (Grant No: $115 \mathrm{M} 108)$. UOSS is thankful for a TUBA-GEBIP Award. We thank Muzaffer Yıldırım and Prof. Dr. İhsan Gürsel for flow cytometer analysis.

\section{ABBREVIATIONS}

IPTG, isopropyl $\beta$-D-1-thiogalactopyranoside; aTc, anhydrotetracycline; TEVp, tobacco etch virus protease; TI-SS, type I 
secretion system; TIII-SS, type III secretion system; POI, protein-of-interest.

\section{REFERENCES}

(1) Saltepe, B., Kehribar, E. S., Su Yirmibeşoğlu, S. S., and Seker, U. O. S. (2018) Cellular Biosensors with Engineered Genetic Circuits. ACS sensors 3, 13-26.

(2) Guet, C. C., Elowitz, M. B., Hsing, W. H., and Leibler, S. (2002) Combinatorial synthesis of genetic networks. Science 296, 1466-1470.

(3) Wang, B. J., Kitney, R. I., Joly, N., and Buck, M. (2011) Engineering modular and orthogonal genetic logic gates for robust digital-like synthetic biology. Nat. Commun..

(4) Stanton, B. C., Nielsen, A. A. K., Tamsir, A., Clancy, K., Peterson, T., and Voigt, C. A. (2014) Genomic mining of prokaryotic repressors for orthogonal logic gates. Nat. Chem. Biol. 10, 99-105.

(5) Win, M. N., and Smolke, C. D. (2008) Higher-order cellular information processing with synthetic RNA devices. Science 322, 456460.

(6) Lucks, J. B., Qi, L., Mutalik, V. K., Wang, D., and Arkin, A. P. (2011) Versatile RNA-sensing transcriptional regulators for engineering genetic networks. Proc. Natl. Acad. Sci. U. S. A. 108, 8617-8622.

(7) Green, A. A., Kim, J. M., Ma, D., Ilver, P. A. S., Collins, J. J., and Yin, P. (2017) Complex cellular logic computation using ribocomputing devices. Nature 548, 117.

(8) Bonnet, J., Yin, P., Ortiz, M. E., Subsoontorn, P., and Endy, D. (2013) Amplifying Genetic Logic Gates. Science 340, 599-603.

(9) Siuti, P., Yazbek, J., and Lu, T. K. (2013) Synthetic circuits integrating logic and memory in living cells. Nat. Biotechnol. 31, 448.

(10) Merrick, C. A., Zhao, J., and Rosser, S. J. (2018) Serine Integrases: Advancing Synthetic Biology. ACS Synth. Biol. 7, 299-310.

(11) Courbet, A., Endy, D., Renard, E., Molina, F., and Bonnet, J. (2015) Detection of pathological biomarkers in human clinical samples via amplifying genetic switches and logic gates. Sci. Transl. Med. 7, 289ra83.

(12) Muller, M., Auslander, S., Spinnler, A., Auslander, D., Sikorski, J., Folcher, M., and Fussenegger, M. (2017) Designed cell consortia as fragrance-programmable analog-to-digital converters. Nat. Chem. Biol. 13, 309.

(13) Horbal, L., and Luzhetskyy, A. (2016) Dual control system - A novel scaffolding architecture of an inducible regulatory device for the precise regulation of gene expression. Metab. Eng. 37, 11-23.

(14) Farzadfard, F., and Lu, T. K. (2014) Genomically encoded analog memory with precise in vivo DNA writing in living cell populations. Science 346, 825.

(15) Prokup, A., and Deiters, A. (2015) Engineering a Bacterial Tape Recorder. ChemBioChem 16, 1027-1029.

(16) Roquet, N., Soleimany, A. P., Ferris, A. C., Aaronson, S., and Lu, T. K. (2016) Synthetic recombinase-based state machines in living cells. Science 353, 363.

(17) Kalyoncu, E., Ahan, R. E., Olmez, T. T., and Seker, U. O. S. (2017) Genetically encoded conductive protein nanofibers secreted by engineered cells. RSC Adv. 7, 32543-32551.

(18) Wargacki, A. J., Leonard, E., Win, M. N., Regitsky, D. D., Santos, C. N. S., Kim, P. B., Cooper, S. R., Raisner, R. M., Herman, A., Sivitz, A. B., Lakshmanaswamy, A., Kashiyama, Y., Baker, D., and Yoshikuni, Y. (2012) An Engineered Microbial Platform for Direct Biofuel Production from Brown Macroalgae. Science 335, 308-313.

(19) Steen, E. J., Kang, Y. S., Bokinsky, G., Hu, Z. H., Schirmer, A., McClure, A., del Cardayre, S. B., and Keasling, J. D. (2010) Microbial production of fatty-acid-derived fuels and chemicals from plant biomass. Nature 463, 559-U182.

(20) Claesen, J., and Fischbach, M. A. (2015) Synthetic Microbes As Drug Delivery Systems. ACS Synth. Biol. 4, 358-364.

(21) Widmaier, D. M., Tullman-Ercek, D., Mirsky, E. A., Hill, R., Govindarajan, S., Minshull, J., and Voigt, C. A. (2009) Engineering the Salmonella type III secretion system to export spider silk monomers. Mol. Syst. Biol., DOI: 10.1038/msb.2009.62.

(22) Natarajan, A., Haitjema, C. H., Lee, R., Boock, J. T., and DeLisa, M. P. (2017) An Engineered Survival-Selection Assay for
Extracellular Protein Expression Uncovers Hypersecretory Phenotypes in Escherichia coli. ACS Synth. Biol. 6, 875-883.

(23) Perez-Pinera, P., Han, N. R., Cleto, S., Cao, J. C., Purcell, O., Shah, K. A., Lee, K., Ram, R., and Lu, T. K. (2016) Synthetic biology and microbioreactor platforms for programmable production of biologics at the point-of-care. Nat. Commun., DOI: 10.1038/ ncomms 12211.

(24) Ni, Y., and Chen, R. (2009) Extracellular recombinant protein production from Escherichia coli. Biotechnol. Lett. 31, 1661-1670.

(25) Fernandez, L. A., Sola, I., Enjuanes, L., and de Lorenzo, V. (2000) Specific secretion of active single-chain Fv antibodies into the supernatants of Escherichia coli cultures by use of the hemolysin system. Appl. Environ. Microbiol. 66, 5024.

(26) Reeves, A. Z., Spears, W. E., Du, J., Tan, K. Y., Wagers, A. J., and Lesser, C. F. (2015) Engineering Escherichia coli into a Protein Delivery System for Mammalian Cells. ACS Synth. Biol. 4, 644-654.

(27) Zhang, G. J., Brokx, S., and Weiner, J. H. (2006) Extracellular accumulation of recombinant proteins fused to the carrier protein YebF in Escherichia coli. Nat. Biotechnol. 24, 100-104.

(28) Qian, Z. G., Xia, X. X., Choi, J. H., and Lee, S. Y. (2008) Proteome-based identification of fusion partner for high-level extracellular production of recombinant proteins in Escherichia coli. Biotechnol. Bioeng. 101, 587-601.

(29) Prehna, G., Zhang, G. J., Gong, X. D., Duszyk, M., Okon, M., McIntosh, L. P., Weiner, J. H., and Strynadka, N. C. J. (2012) A Protein Export Pathway Involving Escherichia coli Porins. Structure 20, 1154-1166.

(30) Kotzsch, A., Vernet, E., Hammarstrom, M., Berthelsen, J., Weigelt, J., Graslund, S., and Sundstrom, M. (2011) A secretory system for bacterial production of high-profile protein targets. Protein Sci. 20, 597-609.

(31) Broedel, S. E., Papciak, S. M., and Weiner, J. (2009) Methods for optimizing the secretion of protein in prokaryotes. Patent number US20090148894A1.

(32) Delepelaire, P. (2004) Type I secretion in gram-negative bacteria. Biochim. Biophys. Acta, Mol. Cell Res. 1694, 149-161.

(33) Thomas, S., Holland, I. B., and Schmitt, L. (2014) The type 1 secretion pathway-the hemolysin system and beyond. Biochim. Biophys. Acta, Mol. Cell Res. 1843, 1629-1641.

(34) Song, M., Sukovich, D. J., Ciccarelli, L., Mayr, J., FernandezRodriguez, J., Mirsky, E. A., Tucker, A. C., Gordon, D. B., Marlovits, T. C., and Voigt, C. A. (2017) Control of type III protein secretion using a minimal genetic system. Nat. Commun. 8, 14737.

(35) Sturm, A., Heinemann, M., Arnoldini, M., Benecke, A., Ackermann, M., Benz, M., Dormann, J., and Hardt, W.-D. (2011) The cost of virulence: retarded growth of Salmonella Typhimurium cells expressing type III secretion system 1. PLoS Pathog. 7, e1002143.

(36) Leyton, D. L., Rossiter, A. E., and Henderson, I. R. (2012) From self sufficiency to dependence: mechanisms and factors important for autotransporter biogenesis. Nat. Rev. Microbiol. 10, 213.

(37) Henderson, I. R., Navarro-Garcia, F., Desvaux, M., Fernandez, R. C., and Ala'Aldeen, D. (2004) Type V protein secretion pathway: the autotransporter story. Microbiology and molecular biology reviews $68,692-744$.

(38) Babu, M., Bundalovic-Torma, C., Calmettes, C., Phanse, S., Zhang, Q., Jiang, Y., Minic, Z., Kim, S., Mehla, J., and Gagarinova, A. (2017) Global landscape of cell envelope protein complexes in Escherichia coli. Nat. Biotechnol. 36, 103.

(39) Ramesh, B., Sendra, V. G., Cirino, P. C., and Varadarajan, N. (2012) Single-cell characterization of autotransporter mediated Escherichia coli surface display of disulfide-bond containing proteins. J. Biol. Chem. 287, 38580.

(40) van Ulsen, P., ur Rahman, S., Jong, W. S., DalekeSchermerhorn, M. H., and Luirink, J. (2014) Type V secretion: from biogenesis to biotechnology. Biochim. Biophys. Acta, Mol. Cell Res. 1843, 1592-1611.

(41) Waugh, D. S. (2011) An overview of enzymatic reagents for the removal of affinity tags. Protein Expression Purif. 80, 283-293. 
(42) Fernandez-Rodriguez, J., and Voigt, C. A. (2016) Posttranslational control of genetic circuits using Potyvirus proteases. Nucleic Acids Res. 44, 6493-6502.

(43) Copeland, M. F., Politz, M. C., Johnson, C. B., Markley, A. L., and Pfleger, B. F. (2016) A transcription activator-like effector (TALE) induction system mediated by proteolysis. Nat. Chem. Biol. 12, 254.

(44) Olson, E. J., Hartsough, L. A., Landry, B. P., Shroff, R., and Tabor, J. J. (2014) Characterizing bacterial gene circuit dynamics with optically programmed gene expression signals. Nat. Methods 11, 449.

(45) Qi, L. S., Larson, M. H., Gilbert, L. A., Doudna, J. A., Weissman, J. S., Arkin, A. P., and Lim, W. A. (2013) Repurposing CRISPR as an RNA-guided platform for sequence-specific control of gene expression. Cell 152, 1173-1183.

(46) Cox, R. S., Dunlop, M. J., and Elowitz, M. B. (2010) A synthetic three-color scaffold for monitoring genetic regulation and noise. $J$. Biol. Eng. 4, 10.

(47) Van der Woude, M. W., and Henderson, I. R. (2008) Regulation and function of Ag43 (flu). Annu. Rev. Microbiol. 62, 153. (48) Kjærgaard, K., Hasman, H., Schembri, M. A., and Klemm, P. (2002) Antigen 43-mediated autotransporter display, a versatile bacterial cell surface presentation system. Journal of bacteriology 184, 4197-4204.

(49) Girard, V., Côté, J.-P., Charbonneau, M.-È., Campos, M., Berthiaume, F., Hancock, M. A., Siddiqui, N., and Mourez, M. (2010) Conformation change in a self-recognizing autotransporter modulate bacterial cell-cell interaction. J. Biol. Chem. 285, 10616.

(50) Kapust, R. B., and Waugh, D. S. (2000) Controlled intracellular processing of fusion proteins by TEV protease. Protein Expression Purif. 19, 312-318.

(51) Costa, S., Almeida, A., Castro, A., and Domingues, L. (2014) Fusion tags for protein solubility, purification and immunogenicity in Escherichia coli: the novel Fh8 system. Front. Microbiol. 5, 63.

(52) Waugh, D. S. (2005) Making the most of affinity tags. Trends Biotechnol. 23, 316-320.

(53) Waugh, D. S. TEV Protease FAQ. https://mcl1.ncifcrf.gov/ waugh tech/faq/tev.pdf. Accessed on 21 December 2018.

(54) Clifton, L. A., Skoda, M. W., Le Brun, A. P., Ciesielski, F., Kuzmenko, I., Holt, S. A., and Lakey, J. H. (2015) Effect of divalent cation removal on the structure of gram-negative bacterial outer membrane models. Langmuir 31, 404-412.

(55) Robbins, J., Jr, and Taylor, K. (1989) Optimization of Escherichia coli growth by controlled addition of glucose. Biotechnol. Bioeng. 34, 1289-1294.

(56) Roy, A., Kucukural, A., and Zhang, Y. (2010) I-TASSER: a unified platform for automated protein structure and function prediction. Nat. Protoc. 5, 725-738.

(57) Yang, J. Y., Yan, R. X., Roy, A., Xu, D., Poisson, J., and Zhang, Y. (2015) The I-TASSER Suite: protein structure and function prediction. Nat. Methods 12, 7-8.

(58) Zhang, Y. (2008) I-TASSER server for protein 3D structure prediction. BMC Bioinf., DOI: 10.1186/1471-2105-9-40.

(59) Bergmiller, T., Andersson, A. M., Tomasek, K., Balleza, E., Kiviet, D. J., Hauschild, R., Tkačik, G., and Guet, C. C. (2017) Biased partitioning of the multidrug efflux pump AcrAB-TolC underlies longlived phenotypic heterogeneity. Science 356, 311-315.

(60) Mihalcescu, I., Gateau, M. V., Chelli, B., Pinel, C., and Ravanat, J. L. (2015) Green autofluorescence, a double edged monitoring tool for bacterial growth and activity in micro-plates. Phys. Biol. 12, 066016 .

(61) Burdette, L. A., Leach, S. A., Wong, H. T., and Tullman-Ercek, D. (2018) Developing Gram-negative bacteria for the secretion of heterologous proteins. Microb. Cell Fact. 17, 196.

(62) Gardner, T. S., Cantor, C. R., and Collins, J. J. (2000) Construction of a genetic toggle switch in Escherichia coli. Nature 403, 339.

(63) Davis, J. H., Rubin, A. J., and Sauer, R. T. (2011) Design, construction and characterization of a set of insulated bacterial promoters. Nucleic Acids Res. 39, 1131-1141.
(64) Chen, Y.-J., Liu, P., Nielsen, A. A., Brophy, J. A., Clancy, K., Peterson, T., and Voigt, C. A. (2013) Characterization of 582 natural and synthetic terminators and quantification of their design constraints. Nat. Methods 10, 659. 